\title{
O Desenvolvimento Do Pensamento Pré-Algébrico: Uma Atividade Planejada Para Alunos Dos Anos Iniciais
}

\author{
The Development Of Pre-Algebraic Thinking: \\ An Activity Designed For Early Years Students
}

\author{
Márcia Jussara Hepp Rehfeldt ${ }^{*}$ \\ Universidade do Vale do Taquari - (Univates) \\ Marli Teresinha Quartieri** \\ Universidade do Vale do Taquari - (Univates) \\ Ieda Maria Giongo*** \\ Universidade do Vale do Taquari - (Univates)
}

\begin{abstract}
Resumo
O presente artigo tem como propósito apresentar resultados de uma prática em que foram problematizadas questões que contemplam a segunda concepção da álgebra conforme descrita por Usiskin (1995). O desenvolvimento das atividades envolveu docentes dos Anos Iniciais, em seis cidades localizadas no Vale do Taquari, interior do Rio Grande do Sul. Metodologicamente, trata-se de uma pesquisa qualitativa, com características de estudo de caso. Além de analisados e descritos por atividade, os dados foram gerados por meio de materiais contemplando as respostas dos docentes, gravações, fotografias. Os resultados apontam que: a) na resolução dos problemas, os docentes utilizaram diferentes estratégias; entre elas, desenhos, escritas, esquemas, cálculos usando a aritmética; b) alguns docentes, inicialmente, resolveram as questões na forma algébrica em detrimento do uso do material didático manipulável disponibilizado; c) as atividades algébricas contemplando a segunda concepção de Usiskin (1995) podem ser exploradas com alunos dos Anos Iniciais, concebendo ideias de pensamento pré-algébrico.
\end{abstract}

Palavras-chave: Anos Iniciais; Ensino de Matemática; Álgebra; Pré-álgebra

\begin{abstract}
This study aims at presenting the outcomes of a practice in which the questions problematized encompassed the second algebra conception as described by Usiskin (1995). The participants in this activity were teachers of the Early Years in six cities in the Taquari Valley, countryside of Rio Grande do Sul, Brazil. Regarding its methodology, it is a qualitative research, characterized by case studies. Data were analyzed and described per activity; they were collected through teachers' answers, recordings, and photographs. Outcomes show that: a) in

\footnotetext{
* Doutora em Informática na Educação pela UFRGS. Professora da Univates, Lajeado, RS, Brasil.

E-mail: mrehfeld@univates.br.

** Doutora em Educação pela Unisinos. Professora da Univates, Lajeado, RS, Brasil.

E-mail: mtquartieri@univates.br.

*** Doutora em Educação pela Unisinos. Professora da Univates, Lajeado, RS, Brasil.

E-mail: igiongo@univates.br.
} 
problem-solving, teachers used various strategies, among them: drawings, writings, schemes, calculations using arithmetic; b) initially some teachers solved the problems in the algebraic form, instead of using the available teaching material which could be handled; c) algebraic activities encompassing Usiskin's (1995) second conception may be explored with Early Years students, stimulating ideas of pre-algebraic thinking.

Keywords: Early Years; Teaching of Mathematics; Algebra; Pre-algebra

\section{Introdução}

Este artigo é oriundo de práticas planejadas e exploradas por um grupo de seis professores da Escola Básica, três mestrandos do Programa Mestrado em Ensino de Ciências Exatas, seis bolsistas de Iniciação Científica e alguns voluntários, sob a orientação de três professoras pesquisadoras vinculadas a uma Universidade localizada no interior do Rio Grande do Sul. Os envolvidos integram a pesquisa, ainda em desenvolvimento, denominada "Estratégias metodológicas visando à inovação e reorganização curricular no campo da educação matemática no Ensino Fundamental", cujo projeto foi aprovado pelo Edital OBEDUC 049/2012. Seu objetivo central é problematizar e propor estratégias metodológicas com vistas à inovação e reorganização curricular na disciplina Matemática em seis escolas públicas de Educação Básica do Vale do Taquari, RS.

Após três anos de investigações nas seis escolas parceiras, verificou-se que o ensino de álgebra, em especial no Ensino Fundamental, ainda causava inquietação aos docentes. Ademais, os resultados oriundos de provas simuladas da Prova Brasil, aplicadas aos alunos das referidas escolas, demonstraram baixos índices de acertos em questões que contemplaram a álgebra (REHFELDT et al., 2016).

A partir dessas constatações e em discussões com os integrantes da pesquisa, identificamos a necessidade de planejar novas práticas contemplando a pré-álgebra que pudessem ser exploradas a partir dos Anos Iniciais, haja vista que, usualmente, ocorria uma fenda quando o professor abordava a passagem da aritmética para a algébrica, como comentam Oliveira e Laudares (2015, p. 4). Segundo os autores:

O papel do professor é fundamental para que os estudantes desenvolvam um sentido numérico concomitante ao pensamento algébrico, levando-os a perceber o que há de comum entre as duas, para que consigam fazer a transição da Aritmética para a Álgebra como uma continuidade e não como uma fenda.

Em relação à pré-álgebra, Modanez (2003) alude que ela foi desenvolvida pelos egípcios para resolver problemas geométricos e consistia em representações de grandeza desconhecida, uma vez que o uso de números gerava certa carência para suas reproduções. 
Para Luna e Souza (2013, p. 823), “A pré-álgebra seria o desenvolvimento de alguns aspectos da álgebra, como, por exemplo, a exploração de situações-problema". Dessa forma, o aluno iniciaria a pensar abstratamente, poderia registrar algumas respostas ou mesmo mencioná-las oralmente. Não seriam letras, incógnitas ou variáveis, mas símbolos ou uma forma icônica. De acordo com os autores mencionados, os conteúdos seriam "analisados e abordados de modo a formarem uma rede de significados". Corroboramos essas ideias e entendemos que é possível explorar atividades contemplando o ensino da pré-álgebra nos Anos Iniciais.

Neste cenário, o presente artigo tem como objetivo apresentar resultados de uma prática em que foram problematizadas questões que contemplam a segunda concepção da álgebra - Álgebra como um estudo de procedimentos para resolver certos tipos de problemas na perspectiva de Usiskin (1995), com professores dos Anos Iniciais, considerando aspectos da pré-álgebra. Diante disso, primeiramente, são conceituadas as diferentes concepções, a relevância de pré-álgebra e algumas considerações sobre o seu desenvolvimento nos Anos Iniciais, constituindo-se, assim, o referencial teórico deste estudo. Em seguida, abordam-se a metodologia usada e as atividades que foram planejadas, exploradas e analisadas. A seção análise de resultados expõe as resoluções consideradas diferenciadas pelas professoraspesquisadoras, contemplando estratégias consideradas pré-álgebra. Por fim, são tecidas as considerações finais e os referenciais bibliográficos que subsidiaram o estudo.

\section{2 Álgebra: Conceitos, Concepções E Relevância Nos Anos Iniciais}

Para Usiskin (1995), há quatro concepções da álgebra (Quadro 1), sendo que elas se relacionam com os usos das variáveis de formas diferentes.

\begin{tabular}{|c|c|}
\hline Concepção da álgebra & Uso das variáveis \\
\hline Aritmética Generalizada & $\begin{array}{c}\text { Generalizadoras de modelos } \\
\text { (Traduzir, generalizar) }\end{array}$ \\
\hline Meio de resolver certos problemas ${ }^{1}$ & $\begin{array}{c}\text { Incógnitas, constantes } \\
\text { (resolver, simplificar) }\end{array}$ \\
\hline Estudo das relações & $\begin{array}{c}\text { Argumentos, parâmetros } \\
\text { (relacionar, gráficos) }\end{array}$ \\
\hline Estrutura & $\begin{array}{c}\text { Sinais arbitrários no papel } \\
\text { (manipular, justificar) }\end{array}$ \\
\hline
\end{tabular}

Quadro 1 - As quatro concepções da álgebra na perspectiva de Usiskin (1995) Fonte: Usiskin (1995, p. 20)

Segundo Usiskin (1995, p. 15), na segunda concepção da álgebra, foco deste estudo, “as variáveis são ou incógnitas ou constantes. Enquanto as instruções-chave no uso de uma

\footnotetext{
${ }^{1}$ Esta concepção foi posta em negrito, pois somente ela é discutida neste artigo.
} 
variável como generalizadora de modelos são de traduzir e generalizar, neste caso as instruções-chave são simplificar e resolver". Em outras palavras, são requeridas do aluno a capacidade de resolver questões do tipo $5 x+3=8$. Nesse caso, usualmente, o professor ensina a estratégia "isolando o x" e fazendo a operação inversa, ou seja, primeiro subtrai 3 do número 8 e, posteriormente, divide o resultado por 5. Para Usiskin (1995, p. 15), ao resolver problemas que envolvem a segunda concepção, os discentes apresentam dificuldades, já que necessitam "raciocinar exatamente de maneira contrária à que empregaríamos para resolver o problema aritmeticamente", pois o resultado representa um número que, multiplicado por $5 \mathrm{e}$ adicionado de 3 , resulta em 8 .

Outro exemplo que ilustra a segunda concepção da álgebra proposta por Usiskin (1995) foi descrito por Guimarães (2013, p. 24): "Pensei em um número. Se eu somar 15 com o número que pensei, o resultado dará 38. Qual o valor do número pensado?”. Nesse tipo de questão, segundo o autor, o aluno precisa simplificar e resolver. Assim, questionamo-nos sobre como ocorre esse processo de simplificação e resolução. Para um aluno do Ensino Fundamental, simplificar ou traduzir a linguagem natural para a simbólica é uma tarefa árdua e complexa. Ramos, Silva e Oliveira (2013, p. 7) também comentam que a "segunda concepção [de Usiskin] trata da manipulação e simplificação das expressões para encontrar o resultado [...]". Mas como propor atividades que favoreçam a manipulação e a simplificação? É possível iniciar tais processos propondo o ensino da pré-álgebra?

Ibrahim, Rezende e Silva (2013, p. 149) ressaltam que "O desenvolvimento do pensamento algébrico se inicia tão logo a criança começa a generalizar algumas relações, por exemplo, as relações de igualdade e a de ordem”. Branco (2013), apoiada em Kieran (1992), explicita que, na aritmética, o sinal "=" é usado como separador entre o procedimento e o resultado. No entanto, esse mesmo sinal requer novos significados quando estes estiverem presentes nas expressões algébricas e equações. Logo, é relevante que o professor explicite e conheça as diferentes concepções do sinal de igualdade.

Matos, Branco e Ponte (2005, p. 54-59) recomendam que os alunos possam vivenciar desde cedo experiências de "aprendizagens que os preparem para um futuro contacto com símbolos e expressões algébricas”. Fiorentini, Fernandes e Cristovão (2005, p. 5) aludem que

A iniciação ao desenvolvimento do pensamento algébrico, portanto, pode ocorrer já desde os primeiros anos de escolarização. Segundo o educador matemático Ken Milton (1989) 'aquilo que ensinamos em aritmética e a forma como a ensinamos têm fortes implicações para o desenvolvimento do pensamento algébrico'.

Embasadas, portanto, em Ibrahim, Rezende e Silva (2013), Matos, Branco e Ponte 
(2005) e Fiorentini, Fernandes e Cristovão (2005), elaboramos uma sequência de três atividades, à luz da segunda concepção de Usiskin (1995), que foi explorada com docentes dos Anos Iniciais, com o intuito de favorecer a construção do pensamento algébrico.

\section{Metodologia}

Este estudo pode ser caracterizado como sendo de abordagem qualitativa com aproximações de estudo de caso. De acordo com Lakatos e Marconi (2011, p. 269),

A metodologia qualitativa preocupa-se em analisar e interpretar aspectos mais profundos, descrevendo a complexidade do comportamento humano. Fornece análise mais detalhada sobre as investigações, hábitos, atitudes, tendências de comportamento.

Em nossa investigação, descrevemos e analisamos, detalhadamente, o desenvolvimento realizado pelos docentes que atuavam nos Anos Iniciais no intuito de compreender como eles resolviam questões que contemplavam a segunda concepção de Usiskin (1995). Quanto aos procedimentos, compreendemos esta investigação como tendo aproximações com o estudo de caso.

De acordo com Yin (2010, p. 39), um estudo de caso "é uma investigação empírica que investiga um fenômeno contemporâneo em profundidade e em seu contexto de vida real, especialmente quando os limites entre o fenômeno e o contexto não são claramente evidentes". Em adição, para Gil (2009, p. 15), "os estudos de caso possibilitam estudar com profundidade o grupo, organização ou fenômeno, considerando suas múltiplas dimensões". Em nosso estudo, averiguamos com detalhes seis distintos grupos de professores, os quais chamamos de docentes ao longo do texto, com quem foram exploradas as diferentes atividades.

Como já mencionado, os investigados constituíam um grupo de 50 docentes que ministravam aulas nas seis escolas parceiras das quais também advinham parte dos pesquisadores. Ao nos referirmos aos professores pesquisadores, estamos nomeando os três professores que atuavam na Universidade e aos seis docentes que integravam a pesquisa e também lecionavam nas referidas escolas. Estas são denominadas A, B, C, D, E e F.

As etapas de planejamento ocorreram de forma conjunta e envolveram as seguintes ações: a) estudo dos referenciais teóricos, entre eles as diferentes concepções da álgebra de Usiskin (1995); b) discussão e compreensão das diferentes concepções da álgebra; c) planejamento de sequências didáticas contemplando as distintas concepções; d) escrita das 
atividades; e) preparo dos materiais necessários para exploração das atividades; f) resolução e problematização das sequências didáticas com vistas a encontrar lacunas e/ou inconsistências; g) deslocamento da equipe de professores pesquisadores até as escolas para exploração das atividades; h) coleta dos materiais utilizados pelos docentes no desenvolvimento das respostas; i) escrutínio dos materiais para posterior escrita do artigo.

Os instrumentos de coleta de dados foram constituídos de diário de bordo, fotografias e materiais escritos pelos docentes no decorrer do desenvolvimento das atividades. Para Machado (2002, p. 260), “o Diário de Bordo é a compilação de todas as anotações que um encenador-criador faz durante a escritura, montagem e encenação do espetáculo sobre o qual, futuramente, sua dissertação ou tese vai tematizar e discutir". Em nosso caso, temos o artigo aqui produzido. Quanto às imagens, Medina Filho (2013, p. 264) esclarece que

[...] não há pensamento apenas verbal, sem a presença de imagens. Há uma relação dinâmica entre os dois códigos de pensamento e de comunicação, o imagético e o verbal. São duas dimensões inseparáveis da vida, do pensamento e da comunicação.

Assim, nosso artigo é permeado por imagens e descrições da representação de tais imagens. Ainda, nesta seção, cabe apresentar as três atividades que compõem a sequência didática e como elas foram propostas ao grupo de professores.

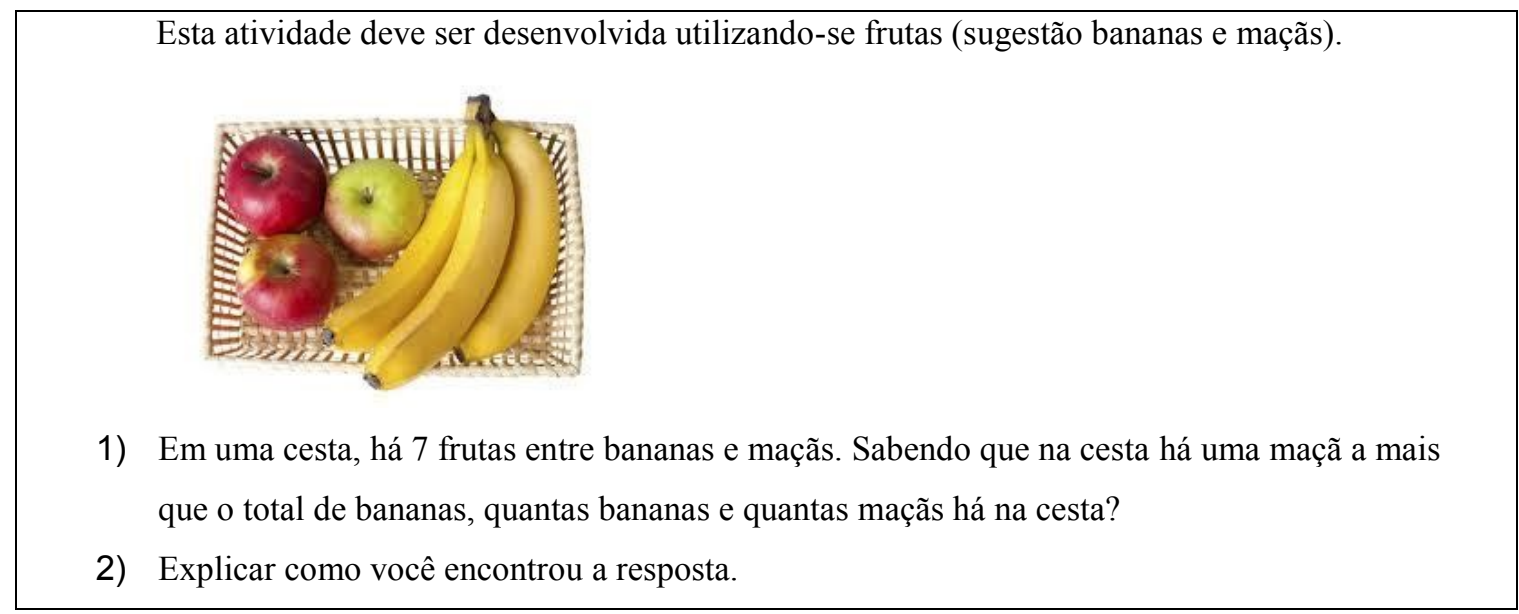

Figura 1 - Primeira atividade apresentada aos grupos de docentes Fonte: Os autores

Para responder às questões acima, os docentes receberam imagens de uma cesta contendo 5 bananas e 5 maçãs conforme ilustra a Figura 2. O intuito era fornecer-lhes materiais didáticos manipuláveis. Estes, segundo Scolaro (2008), possibilitam ao aluno tocar, sentir, manipular, movimentar, favorecendo, assim, a representação de uma ideia e, por conseguinte, atribuir um significado àquilo que está sendo representado. 


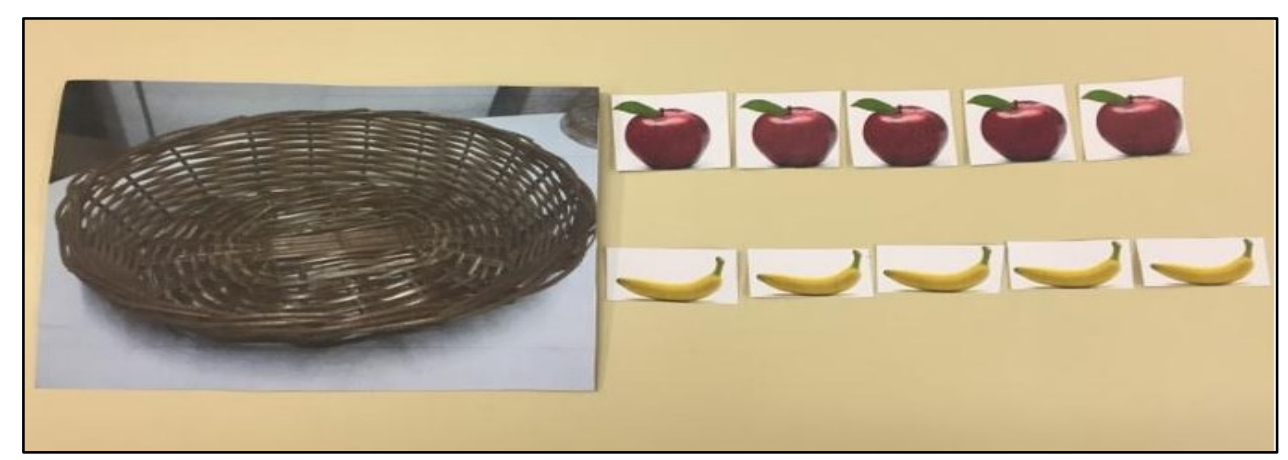

Figura 2 - Materiais didáticos manipuláveis entregues aos docentes para resolver a primeira atividade Fonte: autores do artigo, 2017

Desenvolvida a atividade 1 e socializados os seus resultados, propusemos a 2 . No entanto, para esta, nenhum material didático manipulável foi entregue aos docentes. Assim, eles foram desafiados a pensar em outra estratégia. Nada a respeito dos referidos materiais foi dito aos investigados.

1) Uma turma de $8^{\circ}$ ano da escola, há 25 alunos entre meninos e meninas. Sabendo que o número de meninas supera em 7 o número de meninos, quantos meninos e meninas há nesta turma?

2) Explicar como você encontrou a resposta.

Figura 3 - Segunda atividade apresentada aos grupos de docentes Fonte: Os autores

Após socializar novamente os resultados em grande grupo, entregamos aos investigados a atividade 3 com dois pratos de plásticos (a instrução era: Utilizar moedas e cubinhos na quantidade ilustrada a seguir). O primeiro continha $\mathrm{R} \$ 2,80 \mathrm{em}$ moedas, sendo 2 de $\mathrm{R} \$ 1,00 ; 1$ de $\mathrm{R} \$ 0,50 ; 1$ de $\mathrm{R} \$ 0,25$ e 1 de $\mathrm{R} \$ 0,05$. No segundo prato, foram colocadas 5 moedas, totalizando $\mathrm{R} \$ 2,05$, sendo 1 de $\mathrm{R} \$ 1,00 ; 1$ de $\mathrm{R} \$ 0,50 ; 2$ de $\mathrm{R} \$ 0,25 ; 1$ de $\mathrm{R} \$ 0,05$; além de 3 cubinhos representando valores iguais. A Figura 2 ilustra o material didático manipulável entregue aos docentes.

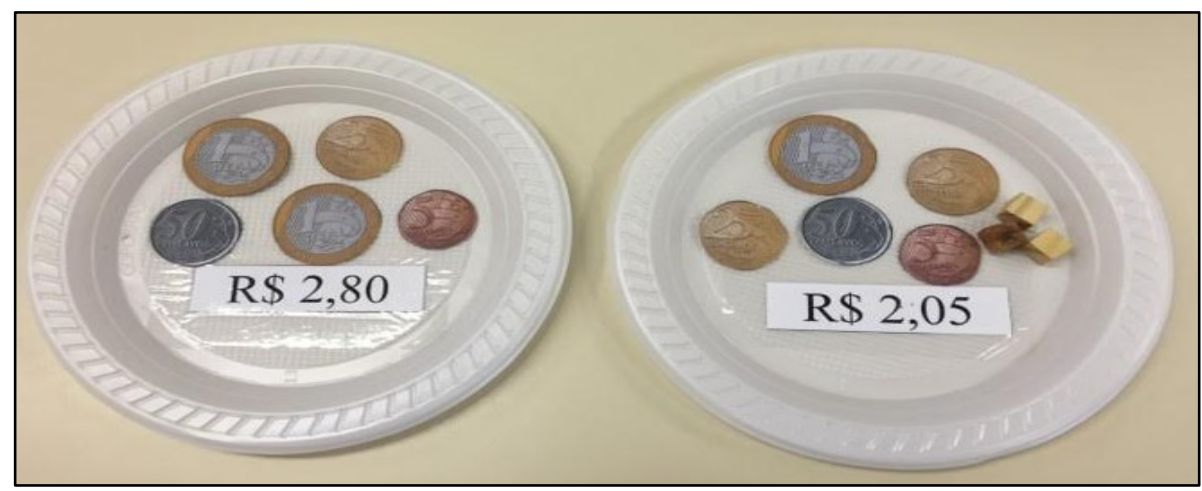

Figura 4 - Materiais didáticos manipuláveis entregues aos docentes para resolver a terceira atividade Fonte: Os autores 
Todas as soluções propostas aos docentes das seis escolas foram lidas, avaliadas, discutidas, e algumas delas estão contempladas neste artigo. O critério de escolha está alicerçado em resoluções ou estratégias que ilustram um pensamento que nosso grupo de pesquisadores caracterizou como pré-algébrico embora também comentássemos outras soluções. A análise de dados foi elaborada de forma descritiva. As discussões se encontram na seção análise de resultados.

\section{Análise de resultados}

Tão $\operatorname{logo}$ a atividade 1 e os materiais didáticos manipuláveis foram entregues aos investigados, nas seis escolas, a maioria dos docentes iniciou os cálculos. Algumas proposições de soluções, consideradas por nosso grupo algébricas, foram expressas da seguinte forma: a) $x+(x+1)=7$, uma equação ou b) $x+y=7$ e $x=y+1$ um sistema de equações.

Para Usiskin (1995, p. 15), na segunda concepção da álgebra, "as variáveis são ou incógnitas ou constantes" e, nesse caso específico, representadas, na primeira equação, por x e, no sistema de equações, por x e y. Assim, para resolver o problema, são requeridas habilidades de tradução e solução. No entanto, os docentes foram instigados a usarem os materiais manipuláveis embora afirmassem que haviam, enquanto alunos, aprendido álgebra somente por meio de cálculos abstratos. Para Dante (2005, p. 60), é relevante "criar oportunidades para crianças usarem materiais manipuláveis". Ainda de acordo com o autor, "a abstração de ideias tem sua origem na manipulação e atividades mentais a ela associadas" (DANTE, 2005, p. 60). Polli e Figueiredo (2017, p. 4), embasados em Lorenzato (2006), aludem que, para se chegar ao abstrato, é necessário partir do concreto e, nesse aspecto, "os materiais manipuláveis atuam como elementos de mediação do processo de ensino e de aprendizagem”. Por meio deles, os alunos podem conceber ideias e representá-las.

Como nosso intuito era oportunizar também o ensino e a aprendizagem da pré-álgebra, instigamos os docentes a buscarem soluções diferenciadas que alunos dos Anos Iniciais pudessem representar. De acordo com Ibrahim, Rezende e Silva (2013), Matos, Branco e Ponte (2005), Modanez (2003) e Fiorentini, Fernandes e Cristovão (2005), o desenvolvimento do pensamento algébrico pode ser iniciado assim que a criança começa a generalizar algumas relações de igualdade e de ordem. Isso pode ser realizado por meio de vivências desde cedo, 
com vistas a favorecer a transição da aritmética para a álgebra, como apontam Oliveira e Laudares (2015).

Nesse contexto, o Grupo 2 da escola 6 apresentou a seguinte resposta, expressa na Figura 5.

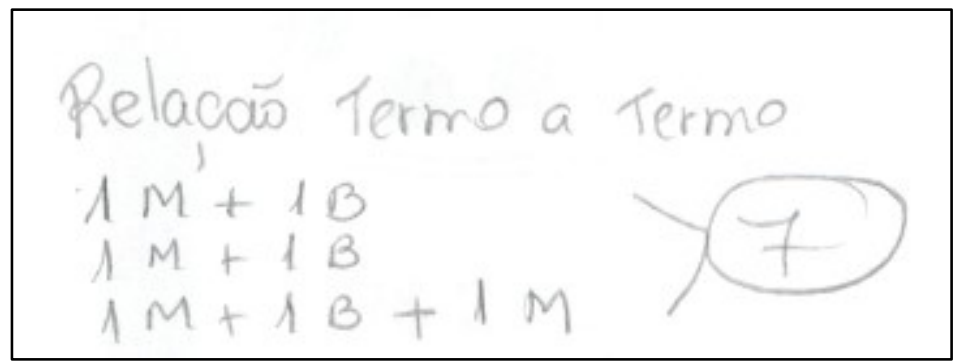

Figura 5 - Estratégia proposta pelo Grupo 2 da escola 6 Fonte: A pesquisa

De acordo com o grupo, os integrantes foram colocando 1 maçã e 1 banana na cesta, usando "termo a termo". A partir da informação de que deveriam ter 1 maçã a mais, inseriram-na e verificaram que havia 7 frutas. De forma similar, o grupo 6 da escola $\mathrm{C}$ representou, por meio de desenho, que havia 4 maçãs e 3 bananas, como mostra a Figura 6.

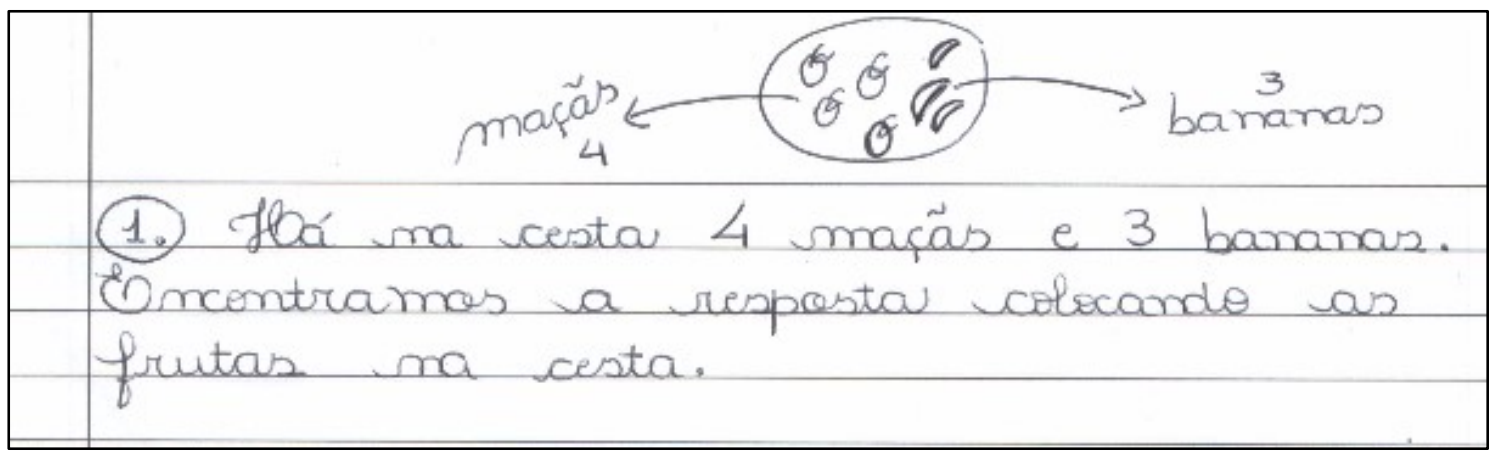

Figura 6 - Solução proposta pelo Grupo 6 da escola C Fonte: A pesquisa

O grupo 1 da escola B corroborou essa ideia expressando-se da seguinte forma quanto à estratégia de resolução: "Colocamos por correspondência: 1 banana e 1 maçã até chegar em 7, sendo que iniciamos pela maçã, já que maçã há uma a mais".

Ao analisarmos a forma como os docentes se expressaram, constatamos que eles usaram a estratégia de adição para chegar ao total de 7 frutas. Ademais, contaram usando o "termo a termo" ou correspondência, inserindo um par de frutas de cada vez. Distintamente dos grupos anteriormente mencionados, o Grupo 3 da escola $\mathrm{C}$ posicionou as 10 figuras que representavam as frutas na cesta e foram retirando 2 de cada vez, utilizando a estratégia da subtração. Como ainda restavam 8 frutas na cesta, releram a questão e retiraram a imagem da banana, já que havia 1 maçã a mais conforme expresso no excerto da Figura 7. 


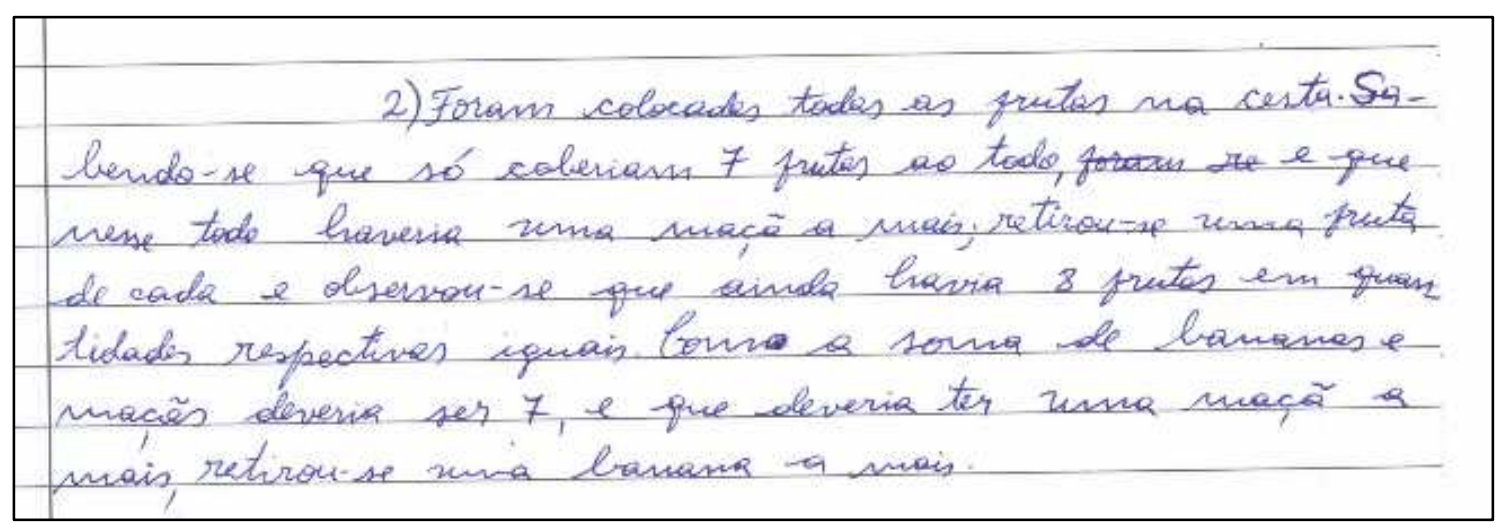

Figura 7 - Descrição feita pelo Grupo 3 da escola C Fonte: A pesquisa

Como podemos observar, a atividade suscitou diferentes estratégias: colocar termo a termo, adicionar 1 de cada vez, posicionar todas e retirar as sobras, além das estratégias algébricas utilizando as incógnitas $\mathrm{x}$ e $\mathrm{y}$. Nesse sentido, podemos observar que as estratégias iniciais expressas pelos docentes não utilizaram incógnitas, mas sim desenhos ou escritas oriundas do material didático manipulável entregue aos docentes. Entendemos que esse tipo de questão contemplando o pensamento pré-algébrico pode ser proposto aos alunos como aludem Ibrahim, Rezende e Silva (2013), Matos, Branco e Ponte (2005), Modanez (2003) e Fiorentini, Fernandes e Cristovão (2005). Tal representação dos alunos dos Anos Iniciais é possível de ser comparada à representação egípcia à qual Modanez (2003) se refere.

De forma semelhante à atividade 1 , os docentes resolveram a de número 2. Alguns representaram a solução por meio de uma equação $x+(x+9)=16$ ou do sistema linear $x+y=25$ e $x=y+7$. No entanto, nosso olhar estava à busca de representações as quais consideramos ter um pensamento pré-algébrico. Neste sentido, destacamos a estratégia usada pelo Grupo 1 da escola B (Figura 8):

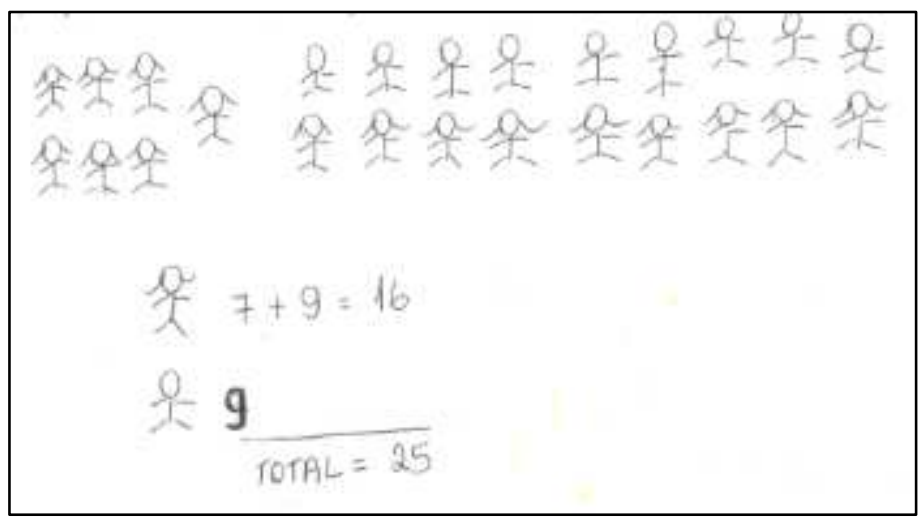

Figura 8 - Representação do Grupo 1 da escola B Fonte: A pesquisa 
Na representação, o Grupo 1, inicialmente, desenhou as 7 meninas que havia a mais no grupo. Posteriormente, dividiram o número de alunos que sobrou em igual quantidade de meninas e meninos, resultando 9 de cada gênero. A partir disso, criaram uma legenda (ícones) e afirmaram que havia 9 meninos e $9+7=16$ meninas. Com relação às reproduções icônicas, Magina et al (2010) observaram em um estudo envolvendo adição e subtração, realizado com 1021 estudantes dos Anos Iniciais da Bahia, que poucos deles usaram diferentes tipos de representações. Em adição, ainda mencionaram que isso pode ter relação com o fato de os docentes não incentivarem outras formas de registros.

Utilizando diferente representação, mas a mesma estratégia, o Grupo 3 da escola C escreveu outro modo de resolução conforme expresso na Figura 9.

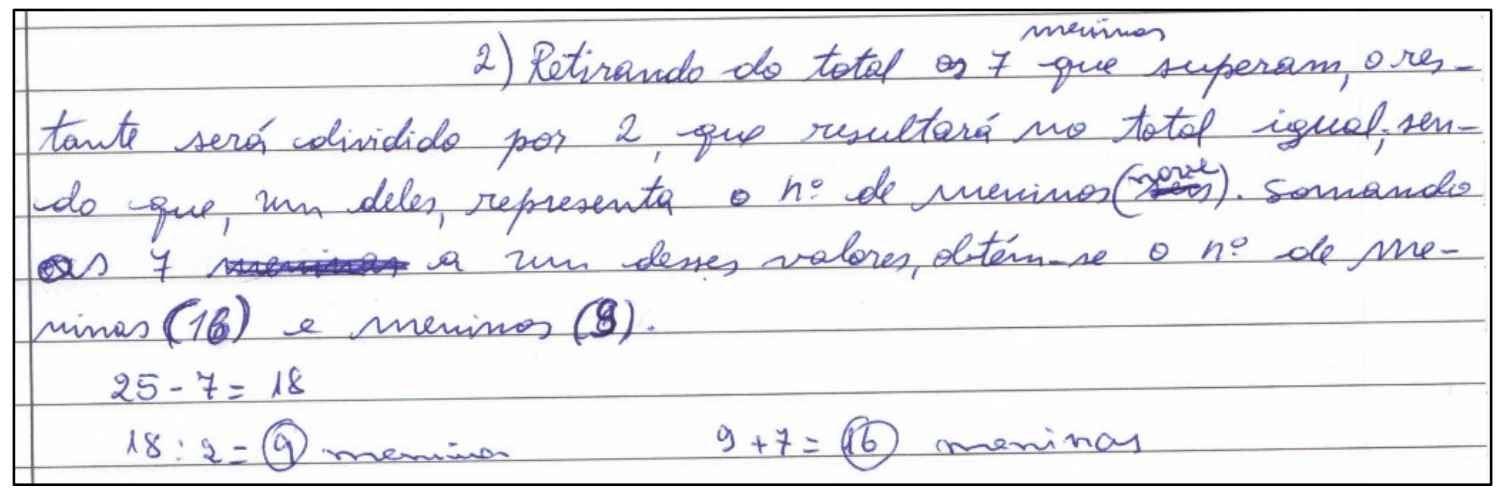

Figura 9 - Representação da resposta para a segunda atividade do Grupo 3 da escola C Fonte: A pesquisa

Como podemos observar, inicialmente, o grupo subtraiu 7 de 25, resultando 18 crianças. Estas foram divididas, de forma igual, em meninos e meninas. Diferentemente da representação anterior, em que foram usadas representações icônicas, o Grupo 3 descreveu sua forma de pensar.

Outra forma de representação foi utilizada pelo Grupo 1 da escola D (Figura 10), que foi representando termo a termo as meninas e os meninos, escrevendo os pares até 18, ou seja, 9 duplas. A partir disso, registraram os números referentes às meninas a mais, ou seja, 7 números, do 19 ao 25. Logo após a representação, confirmaram os cálculos ilustrando a soma total que foi de 25 alunos. 


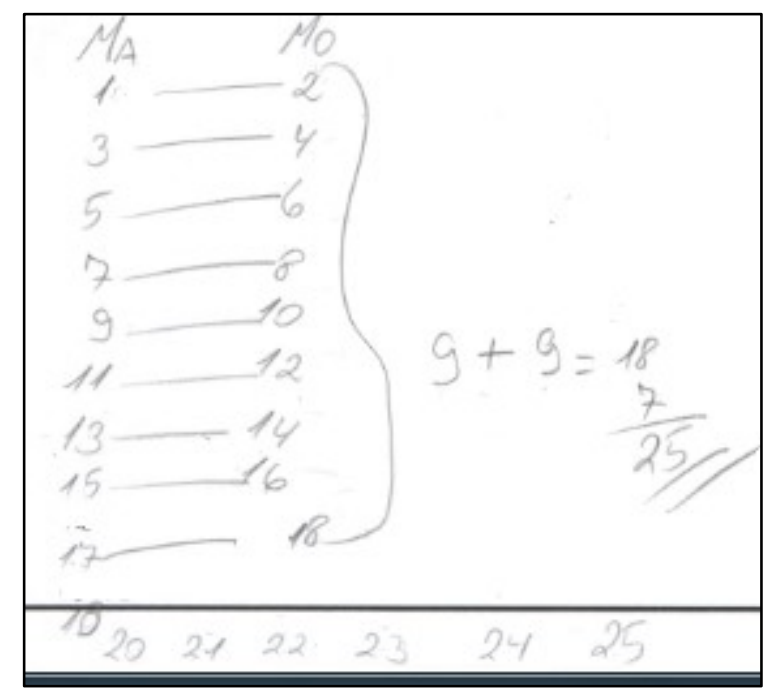

Figura 10 - Representação do Grupo 1 da escola D Fonte: A pesquisa

Diferentemente da atividade 1, em que fornecemos materiais didáticos manipuláveis, aqui esperávamos que os docentes usassem alguma estratégia semelhante, o que de fato ocorreu. Assim, utilizaram desenhos e representações de crianças, agrupadas em meninos e meninas, o que possivelmente formou uma rede de sentidos à que se referem Luna e Souza (2013). Acerca da introdução da álgebra, Oliveira e Laudares $(2015$, p. 3) comentam que
A introdução desse conteúdo de maneira formal, tratando de equações, sem relacioná-lo com a Aritmética e situações vivenciadas no dia a dia, não permite aos estudantes produção de significados, dificultando assim que estes identifiquem o modo como as duas se relacionam. Se o aluno não é capaz de apropriar-se dos conceitos algébricos ele não desperta o prazer de aprendê-los.

Assim, compreendemos que a atividade suscitou ideias que produziram sentidos aos quais se referem Luna e Souza ou significados conforme aludem Oliveira e Laudares (2015). Ademais, concordamos que iniciar a álgebra sem apropriar-se dos conceitos algébricos pode despertar ojeriza à Matemática, bem como contribuir para a abertura de fenda ainda maior na passagem do pensamento aritmético para o algébrico, como apregoam Oliveira e Laudares (2015).

Por fim, analisamos a atividade $3 \mathrm{em}$ que foi abordada a ideia de uma equação do $1^{\circ}$ grau. Os docentes deveriam descobrir quanto valia cada cubinho para que a igualdade entre as bandejas fosse verdadeira. Em uma delas, estavam moedas perfazendo R $\$ 2,80$; na outra, 3 cubinhos e R \$2,05 em moedas.

A maioria dos grupos nas seis escolas usou a aritmética para resolver as questões como ilustra a Figura 11. 


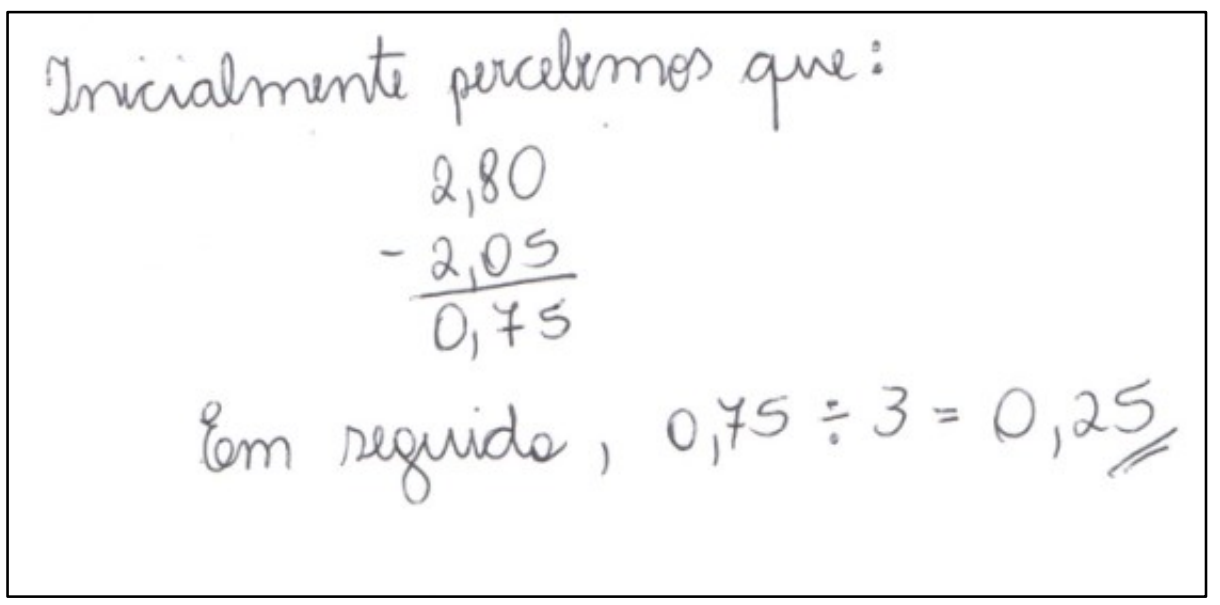

Figura 11 - Estratégia usada pelo Grupo 5 da escola B na atividade 3 Fonte: A pesquisa

A estratégia usada pelo Grupo 5 da escola B foi a de subtrair o valor de R\$2,05 que estava na bandeja. O restante do valor corresponderia ao dos 3 cubos. Por isso, dividiram o resultado $\mathrm{R} \$ 0,75$ por 3 . Distintamente, outros docentes usaram a álgebra e escreveram a equação $3 x+2,05=2,80$, como pode ser visto na representação do Grupo 8 da escola $\mathrm{F}$ (Figura 12):

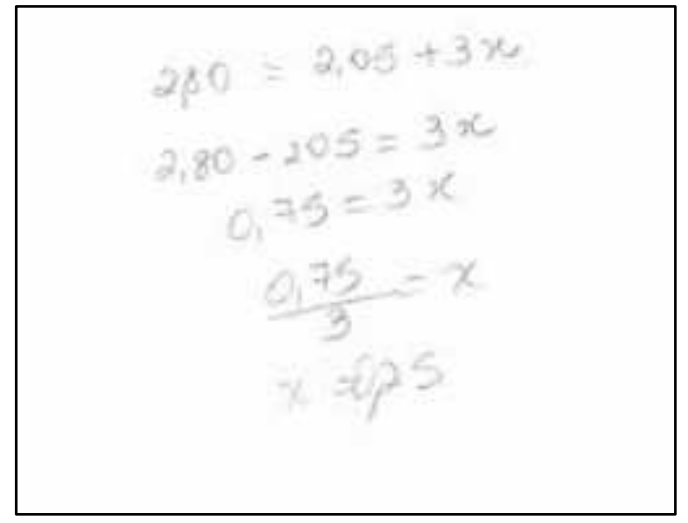

Figura 12 - Equação expressa pelos docentes do Grupo 8 da escola $\mathrm{F}$ Fonte: A pesquisa

Aqui é possível observar a álgebra como meio de resolver certos problemas, segunda concepção de Usiskin (1995). Nela, está explícita a variável x que, nesse caso, representa uma incógnita, ou seja, o valor desconhecido de cada cubinho.

No entanto, o objetivo deste artigo é observar e enfatizar estratégias que docentes dos Anos Iniciais poderiam explorar com seus alunos usando o pensamento pré-algébrico. Nesse sentido, as Figuras 13 e 14 ilustram diferentes maneiras de resolver o problema. 


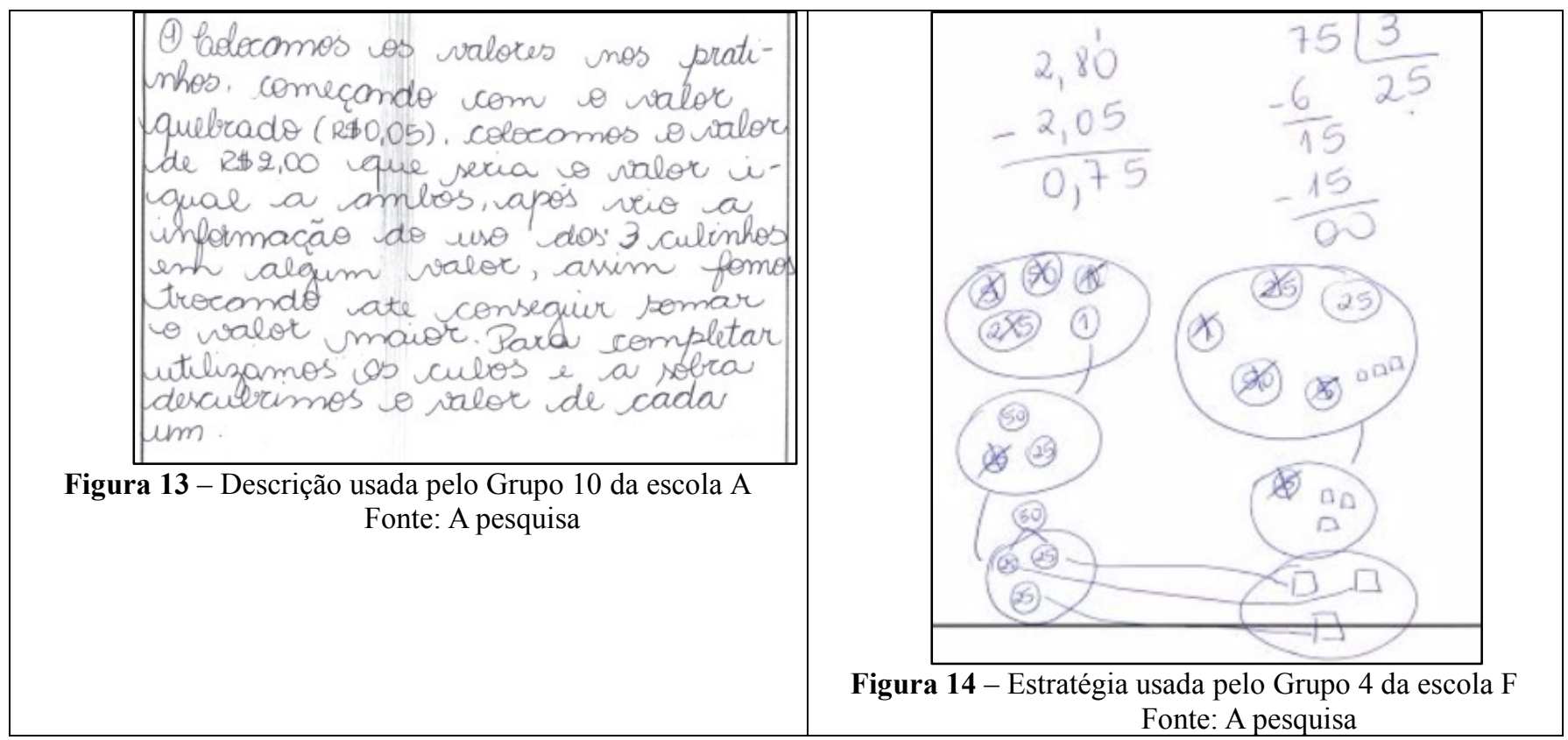

As Figuras 13 e 14 expressam ideias que representam uma equação; logo, uma igualdade expressa por valores nos 2 diferentes pratos. Especificamente, na Figura 14, os docentes retiraram as mesmas quantias de ambos, representadas pelas setas que ilustram a correspondência (Figura 15).

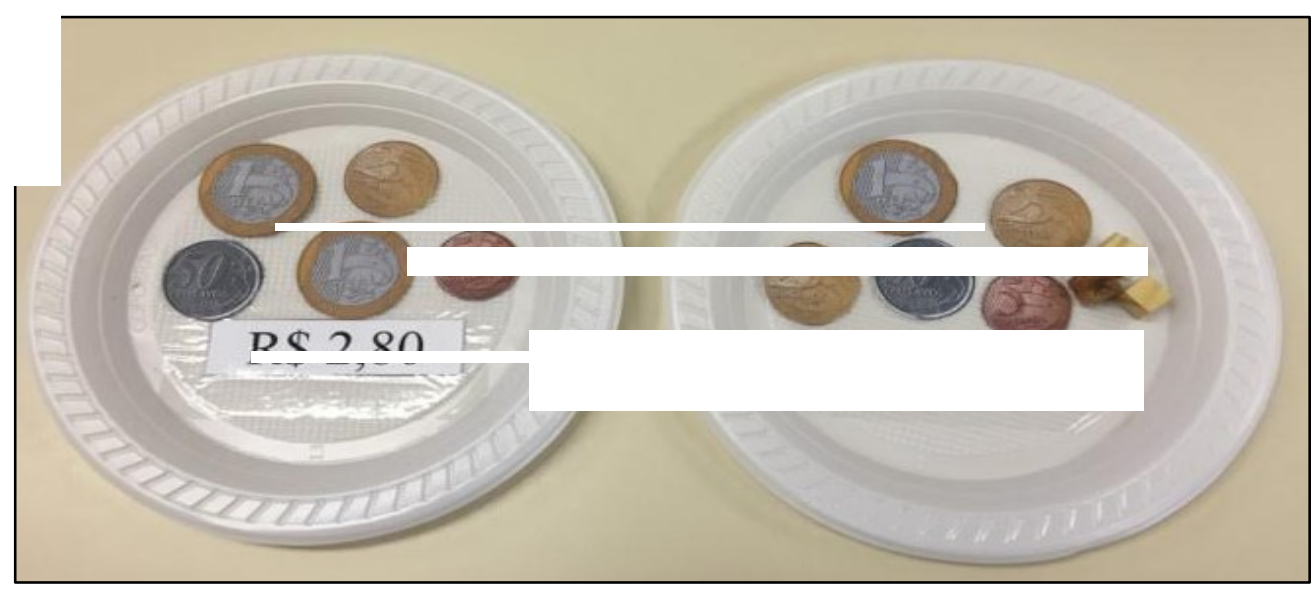

Figura 15 - Esquema de representação do pensamento Fonte: Os autores

Em seguida, os docentes substituíram a moeda de $\mathrm{R} \$ 1,00$ por 1 de $\mathrm{R} \$ 0,50$ e 2 de $\mathrm{R} \$$ 0,25 . Como havia 1 de $\mathrm{R} \$ 0,25$ no prato 2 , retiraram de ambos o mesmo valor, ou seja, $\mathrm{R} \$$ 0,25 de cada. Dessa forma, resultaram, no primeiro prato, 1 moeda de $\mathrm{R} \$ 0,50$ e 2 de 0,25 centavos; no 2, apenas os 3 cubinhos. Por fim, efetivaram a última troca, substituindo a moeda de R\$ 0,50 por 2 de $\mathrm{R} \$ 0,25$. Assim, ficaram com 3 de $\mathrm{R} \$ 0,25$ no prato 1 e os 3 cubinhos no 2. Logo, cada cubinho vale $\mathrm{R} \$ 0,25$. Isso está evidenciado pelas flechas que os docentes desenharam na Figura 14. 


\section{Considerações finais}

Este artigo teve como objetivo apresentar e problematizar alguns resultados oriundos de uma prática em que foram exploradas três questões que contemplam a segunda concepção da álgebra (USISKIN, 1995). De acordo com o autor, nessa concepção, a álgebra é entendida como uma maneira de resolver certos problemas; e as variáveis, como incógnitas. Do aluno, são requeridas as habilidades de resolver e simplificar o problema.

No caso dos 3 problemas apresentados, a prática foi realizada com docentes dos Anos Iniciais os quais vivenciaram a experiência de resolver as questões em pequenos e socializar as respostas em grande grupo. Os docentes das seis escolas parceiras solucionaram as questões usando diferentes estratégias. Nas atividades 1 e 3, após alguma resistência, utilizaram os materiais didáticos que lhes foram concedidos; na falta destes, na questão 2, alguns grupos optaram por realizar representações icônicas.

As diferentes estratégias usadas pelos docentes - aritmética, equação, equivalência nos remetem às ideias de Amado e Carreira (2012). Para as autoras, os alunos não têm algoritmos ou procedimentos pré-construídos que garantam a solução de um problema; ao contrário, eles precisam construí-los. Nesse sentido, podemos entender que explorar questões dessa forma auxiliam no desenvolvimento da criatividade como Gontigo (2006) propõe. Para o autor, a criatividade em matemática tem relação com a capacidade de encontrar distintas maneiras para resolver problemas, criar fórmulas, inventar métodos que sejam diferentes dos tradicionais.

Quanto às representações, escreveram-se equações e sistemas de equações como usualmente têm sido resolvidos em sala de aula. No entanto, neste estudo, focamos estratégias diferentes das chamadas tradicionais e encontramos desenhos, escritas, esquemas, cálculos usando a aritmética que nos deram indícios de criatividade conforme menciona Gontijo (2006), ou seja, distintas maneiras de resolver, criando fórmulas e métodos; enfim, novas representações.

As diferentes possibilidades de representações nos levam a acreditar que a álgebra pode ser explorada nos Anos Iniciais, iniciando, assim, os estudos de uma pré-álgebra, uma vez que, como alude Gómez-Granell (1998), o domínio da linguagem matemática, em especial na álgebra, é considerado um grande desafio para o ensino da Matemática. Esses resultados também foram corroborados por Magalhães (2016) em seu estudo com alunos do $7^{\circ}$ que apresentaram problemas de generalizações e dificuldades na escrita do pensamento 
algébrico. Diante desse contexto, entendemos que atividades que envolvem o pensamento préalgébrico são possíveis de serem desenvolvidas da mesma forma que propõem Ibrahim, Rezende e Silva (2013), Matos, Branco e Ponte (2005), Modanez (2003) e Fiorentini, Fernandes e Cristovão (2005).

\section{Referências}

AMADO, N.; CARREIRA, S. Um olhar sobre uma competição matemática na Web - a resolução de problemas para além da sala de aula. Revista Educação e Matemática, p. 13-18, set-out, 2012.

BRANCO, N. C. V. O desenvolvimento do pensamento algébrico na formação inicial de professores dos primeiros anos, 2013. Tese (doutoramento) - Doutoramento em educação Didática da Matemática, Universidade de Lisboa, Lisboa/Portugal, 2013.

DANTE, Luiz Roberto. Didática da Resolução de Problemas de Matemática. 12a edição. São Paulo, 2005.

FIORENTINI, D.; FERNANDES, F.; CRISTÓVÃO, E. Um estudo das potencialidades pedagógicas das investigações matemáticas no desenvolvimento do pensamento algébrico. In: SEMINÁRIO LUSO-BRASILEIRO DE INVESTIGAÇÕES MATEMÁTICAS NO CURRÍCULO E NA FORMAÇÃO DO PROFESSOR, 2005, Lisboa. Anais... Lisboa: Faculdade de Ciências da Universidade de Lisboa, 2005. Disponível em:

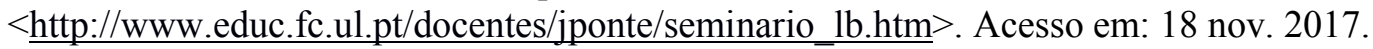

GIL, A. C. Como elaborar projetos de pesquisa. 4ed. São Paulo: Atlas, 2009.

GÓMEZ-GRANELL, C. Rumo a uma epistemologia do conhecimento escolar: o caso da educação matemática. In: RODRIGO, M. J.; ARNAY, J. (Orgs.). Domínios do conhecimento, prática educativa e formação de professores. São Paulo: Ática, 1998. p. 15-41.

GONTIJO, C. H. Resolução e Formulação de Problemas: caminhos para o desenvolvimento da criatividade em Matemática. Anais... Recife: Programa de Pós-Graduação em Educação-Centro de Educação - Universidade Federal de Pernambuco, 2006.

GUIMARÃES, J. F. As concepções da álgebra articuladas aos conteúdos de matemática no Ensino Fundamental, 2013. Dissertação (Mestrado) Programa de Pós-Graduação em Educação Matemática. Pontifícia Universidade Católica de São Paulo, São Paulo, 2013.

IBRAHIM, S. A.; SILVA, M. G. da; RESENDE, M. R. Análise das questões da Prova Brasil segundo as concepções algébricas de Usiskin. Revista Encontro de Pesquisa em Educação. Uberaba, v. 1, n.1, pp. $146-159,2013$.

LAKATOS, E. M.; MARCONI, M. de A. Metodologia Cientifica. 6. ed. São Paulo: Atlas, 2011.

LUNA, A. V. de A.; SOUZA; C. C. C. F. Discussões sobre o ensino de álgebra nos anos iniciais do Ensino Fundamental. Educação Matemática Pesquisa. São Paulo, v. 15, Número Especial, pp. 817835, 2013. 
MACHADO, M. M. O Diário de Bordo como ferramenta fenomenológica para o pesquisador em artes cênicas. Sala Preta (USP), v. 2, p. 260-263, 2002. Disponível em: < file:///D:/Downloads/5710172374-1-PB\%20(1).pdf>. Acesso em: 18 nov. 2017.

MAGALHÃES, A. G. de. Construção de conceitos algébricos com alunos do $7^{\circ}$ ano, 2016. Dissertação (Mestrado) - Curso de Ensino de Ciências Exatas, Centro Universitário UNIVATES, Lajeado, 2016. Disponível em: $<$ http://hdl.handle.net/10737/1570>. Acesso em: 18 nov. 2017.

MAGINA, S. M. P.; SANTANA, E. R. dos S.; CAZORLA, I. M; CAMPOS, T. M. M. As estratégias de resolução de problemas das estruturas aditivas nas quatro primeiras séries do ensino Fundamental. Zetetiké, Campinas, v. 18, n. 34, p. 15-49, jul./dez. 2010.

MATOS, A.; BRANCO, N.; PONTE, J. P. Como vai o pensamento algébrico dos alunos? Educação \& Matemática: Revista da Associação de professores de matemática. Lisboa: Torriana, $\mathrm{n}^{\circ}$ 85, p. 5460, nov-dez. 2005.

MEDINA FILHO, A. L. Importância das imagens na metodologia de pesquisa em psicologia social. Psicologia \& Sociedade, n. 25, v. 2, p. 263-271, 2013. Disponível em: $<$ http://www.scielo.br/pdf/psoc/v25n2/03.pdf> . Acesso em: 18 nov. 2017.

MODANEZ, L. Das sequências de padrões geométricos à introdução ao pensamento algébrico. Dissertação (Mestrado) Programa de Pós-Graduação em Educação Matemática. Pontifícia Universidade Católica de São Paulo, São Paulo, 2003.

NATIONAL COUNCIL FO TEACHER OF MATHEMAIS/ NCTM. Princípios e Normas para a Matemática Escolar. Trabalho original publicado em 2000. Tradução da Associação de Professores de Matemática (APM). Lisboa: Associação de Professores de Matemática e Instituto de lnovação Educacional, 2007.

POLLI, C. T. da; FIGUEIREDO, H. R. S. Possíveis aplicações dos materiais manipuláveis no ensino de geometria para os anos iniciais. In: ENCONTRO PARANAENSE DE EDUCAÇÃO

MATEMÁTICA, Unioeste de Cascavel, 2017. Disponível em:

$<$ http://www.sbemparana.com.br/eventos/index.php/EPREM/XIV_EPREM/paper/viewFile/110/18>.

Acesso em: 18 nov. 2018.

OLIVEIRA, S. C.; LAUDARES, J. B. Pensamento algébrico: uma relação entre álgebra, aritmética e geometria. São João del-Rei/ Minas Gerais, 2015. Disponível em:

$<$ http://www.ufjf.br/emem/files/2015/10/PENSAMENTO-ALG\%C3\%89BRICO-UMA-

RELA $\%$ C3\%87\%C3\%83O-ENTRE-\%C3\%81LGEBRA-ARITM\%C3\%89TICA-E-

GEOMETRIA.pdf>. Acesso em: 18 nov. 2017.

RAMOS, C. S.; SILVA, A. B. da; OLIVEIRA, R. C. Os problemas e as concepções de álgebra em uma aula de matemática do sétimo ano. In: Encontro de educação Matemática, 12. Anais ... Curitiba, 2013. Disponível em: http://sbem.web1471.kinghost.net/anais/XIENEM/pdf/618 1434 ID.pdf.

Acesso em: 18 nov. 2017.

REHFELDT, M. J. H.; DENTE, E. C.; BAVARESCO, G.; RAMA, G. R. Simulado da Prova Brasil: análise de questões matemáticas desenvolvidas por alunos do $5^{\circ}$ ano e do $9^{\circ}$ ano em seis escolas públicas do vale do taquari. In: Observatório da educação II: experiências curriculares no ensino de matemática na escola básica. GIONGO, I. M. ; MUNHOZ, A. V. (Org.) - Lajeado: Ed. Evangraf, 2016, p. 235-252.

SCOLARO, M. A. O uso dos Materiais Didáticos Manipuláveis como recurso pedagógico nas aulas de Matemática, 2008. Disponível em:

$<$ http://www.diaadiaeducacao.pr.gov.br/portals/pde/arquivos/1666-8.pdf $>$. Acesso em: 14 nov.2017. 
USISKIN, Z. Concepções sobre a álgebra da escola média e utilizações das variáveis. In: COXFORD, A. F. ; SHULTE, A. P. (Org.). As idéias da álgebra. São Paulo, 1995, p. 9-22.

YIN, R. K. Estudo de caso: planejamento e métodos. 4. ed. Porto Alegre: Bookman, 2010. 